\title{
RULES AND RECENT TRENDS FOR SETTING HEALTH-BASED OCCUPATIONAL EXPOSURE LIMITS FOR CHEMICALS
}

\author{
JOLANTA SKOWROŃ ${ }^{1}$ and SŁAWOMIR CZERCZAK ${ }^{2}$ \\ ${ }^{1}$ Central Institute for Labour Protection - National Research Institute, Warszawa, Poland \\ Department of Chemical, Aerosol and Biological Hazards \\ ${ }^{2}$ Nofer Institute of Occupational Medicine, Lódź, Poland \\ Department of Chemical Safety
}

\begin{abstract}
The working environment is the special case of the non-natural environment created by man in which the increased production activity brings about the concentration of stimulators particularly aggressive to the human organism, such as chemical hazards, noise, vibration, extreme temperatures, and finally, intensified psychological and emotional stress. Depending on the nature and intensity, working environment factors have been classified into dangerous, harmful and annoying. The workers are more and more frequently exposed to dangerous chemicals in the working environment. The chemicals cause many diseases including, in the 1st place, respiratory insufficiency, inflammatory skin conditions, psychoneurological disorders and neoplastic diseases. Occupational exposure limit values (OELs), the main criteria for occupational exposure assessment, constitute an important factor for the safe use of chemicals in the working environment. In Poland, to date there are 524 chemical substances and 19 dusts for which maximum admissible concentrations (MAC) have been established.
\end{abstract}

Key words:

Occupational exposure limit, Chemicals, Legislation, MAC, OEL

\section{THE HISTORY}

The history of establishing occupational exposure levels for agents harmful to health in the working environment in Poland begins around 1956. There were 14 substances for which maximum admissible concentration (MAC) values were established without documentation [1]. The values did not differ from those which were at that time valid in the Soviet Union.
Maximum admissible concentrations for chemical agents were published in the regulation of Ministry of Labour, Earnings and Social Policy in 1982 [2]. Since 1983, occupational exposure limits for chemical and physical agents are established by the Interdepartmental Commission for Maximum Admissible Concentrations and Intensities for Agents Harmful to Health in the Working Environment [3].

\footnotetext{
The publication has been based on the results of Phase II of the National Programme "Safety and working conditions improvement," funded in the years 2011-2013 in the area of tasks related to services for the State by the Ministry of Labour and Social Policy. The programme coordinator: Central Institute for Labour Protection National Research Institute.

Received: March 7, 2014. Accepted: July 18, 2014.

Corresponding author: J. Skowroń, Central Institute for Labour Protection - National Research Institute (CIOP-PIB), Czerniakowska 16, 00-701 Warszawa, Poland (e-mail: josko@ciop.pl).
} 
On 15th December, 2008, the Prime Minister appointed new members of the Commission [4]. The Interdepartmental Commission includes representatives of the health and labor administration, various sectors of industry, representatives of trade unions, employers and of course representatives of research institutes in the fields of occupational medicine and occupational safety. The main responsibility of the Commission is to consider, evaluate and adopt exposure limits for chemical and physical agents in the working environment and submit them to the Minister of Labor and Social Policy, who is responsible for implementing those values into Polish legislation.

The Commission has appointed a Group of Experts for Chemical and Dust Agents, a Group of Experts for Biological Agents and a Group for Physical Agents. Those groups consist of independent experts in the fields of toxicology, occupational medicine and occupational hygiene. The secretariat of the Commission is based at the Central Institute for Labor Protection - National Research Institute (Figure 1).

The MAC values for chemicals are published in the Journal of Law. These are hygienic standards valid for all branches of the national economy [5].

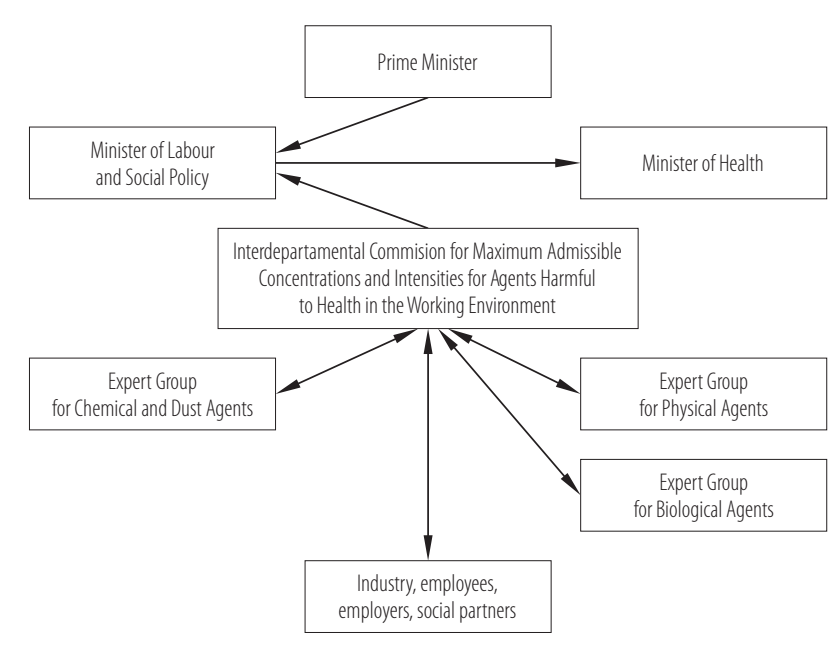

Fig. 1. Polish system for setting occupational limit values of agents harmful to health in the working environment
One of the first-in-the-World systems of establishing and revising occupational exposure limits was launched by the non-governmental corporation of industrial hygienists and safety specialists - American Conference of Governmental Industrial Hygienists ${ }^{\circledR}$ (ACGIH) [6]. The ACGIH was formed in 1938 and released its 1st list of OELs in 1941 [7]. In the European Union (UE), since 1995 [8], the Scientific Committee for Occupational Exposure Limits (SCOEL) has been developing indicative occupational exposure limit values (IOELVs) for chemical agents in the working environment. Directives 98/24/EC [9], 91/322/EWG [10], 2000/39/ EC [11], 2006/15/EC [12], 2009/161/EC [13] contain current lists of indicative values for 122 chemical substances and binding occupational exposure limit values (BOELVs) for 10 substances (98/24/EC [9], 2004/37/EC [14], 2009/148/ EC [15]). In Europe-France, Germany, Sweden, and Finland have developed their national systems of establishing occupational exposure levels for chemicals in the workplace air.

\section{INTRODUCTION}

The Maximum Admissible Concentrations of chemicals (MAC (TWA), OELs) are defined as values the effect of which on workers during their whole productive lives should not cause adverse changes in the state of their health and the health of their next generations. The respective values were based on health criteria and assessment of health risk performed using the latest scientific data. The MACs are based on information available from epidemiological and experimental human and animal studies [5].

According to the type of toxic effects and time of exposure, the following categories of MAC values are used:

- MAC (TWA) - maximum admissible concentration (time-weighted average) - the time-weighted average concentration for a conventional 8-hour workday and a workweek defined in the Labor Code, to which workers may be exposed during their whole working lives, without any adverse effects on their health (also when retired) or on the health of the next generations. 


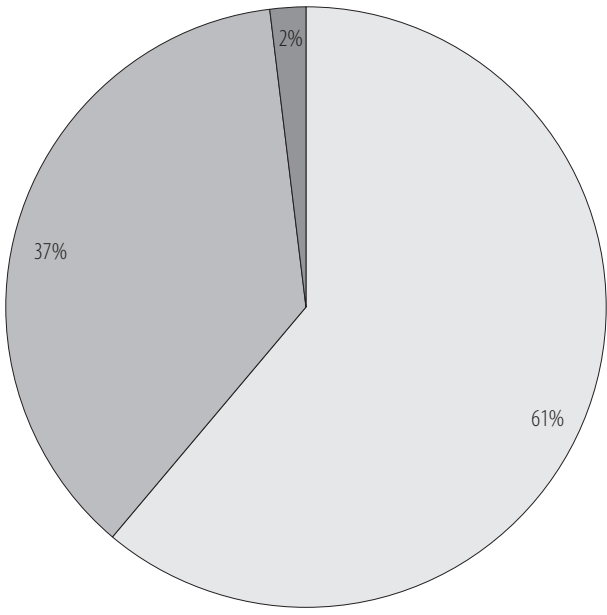

substances for which the MAC (TWA) and the MAC (STEL) were establisched substances for which only the MAC (TWA) were establisched

substances for which only the MAC (ceiling) were establisched

MAC (TWA) - maximum admissible concentration - the time-weighted average concentration; MAC (STEL) - maximum admissible shortterm concentration; MAC (ceiling) - maximum admissible ceiling concentration.

Fig. 2. The chemicals for which MAC (TWA/STEL) or MAC (ceiling) values were established (524 chemicals in the list in 2014)

- MAC (STEL) - maximum admissible short-term concentration - the short-term exposure limit is an average concentration to which workers may be exposed without any adverse health effects if it does not last longer than $15 \mathrm{~min}$ and does not occur more than twice during a workday at interval not shorter than $1 \mathrm{~h}$.

- MAC (Ceiling) - maximum admissible ceiling concentration - ceiling concentration which, because of the threat to workers' health or life, should not be exceeded even instantaneously [5] (Figure 2).

The experts of the Group for Chemicals prepare healthbase documentation for recommended occupational exposure limits along with recommendations on pre-employment and periodical medical examinations and contraindications to exposure and, if possible, on biological tolerance limits.
The documentation prepared by experts is thoroughly reviewed at the meetings of the Group, where the recommended values undergo careful scientific evaluation.

Uniform documentation for each compound includes: (1) Contents, (2) Summary, (3) Substance characterization, uses and occupational exposure, (4) Toxic effects in humans, (5) Toxic effects in laboratory animals, (6) Carcinogenicity, mutagenicity, teratogenicity, embriotoxicity, and effects on reproduction, (7) Toxicokinetics, (8) Mechanism of toxicity, (9) Combined effects, (10) Dose-effect and dose-response relationships, (11) Bases for existing MAC or MAI values and biological tolerance limits, (12) Bases for proposed MAC or MAI values and biological tolerance limits, (13) Methods of determining the agents harmful to health in the air and in biological material, (14) Pre-employment and periodical medical examinations and (15) References [1].

There are 3 major independent steps in the Polish procedure, leading to the establishment of MACs:

- an independent scientific expertise phase (only health criteria and assessment of health risk),

- evaluating and adopting exposure limits for chemicals in the working environment by the Commission and submitting them to the Minister of Labor and Social Policy, who is responsible for implementing those values into legislation,

- a social and interdepartmental dialogue phase through consultation on the labor ministry legislative proposal for MACs.

After the Minister's approval, the MAC lists are published in Journal of Law. They are hygienic standards valid for all branches of the national economy.

In the Polish system, the documentation of MAC values is published quarterly in the publication of the Interdepartmental Commission: Principles and Methods of Assessing the Working Environment, which makes it possible for occupational physicians and sanitary inspectors to become acquainted with the problem. 
The specified MAC values constitute guidelines for the designers of new and updated technologies and products, criteria for the evaluation of working conditions, and a basis for planned preventive activities in industrial plants. Industrial plants are obliged to estimate concentrations of chemicals to facilitate steps intended to keep them below the values specified in the MAC list, and keep records of those estimates. An improvement of working conditions is the aim of those activities [16].

\section{Setting occupational exposure limits}

\section{for substances with threshold effects}

For many substances, it is possible to establish a level at which toxicological reactions no longer appear if the exposure level is sufficiently low, i.e., such substances show no-observed-adverse-effect level (NOAEL). The adverse effects of chemicals on the organism may be classified either as local (corrosive, irritant) or systemic and remote (genotoxic, carcinogenic, embryotoxic, fetotoxic, teratogenic). The evaluation of adverse effects of occupational exposures is carried out in a case-by-case manner [17].

The NOAEL for critical effects is the common point of establishing the occupational exposure limits, preferably from human data, or from chronic toxicity inhalation studies on experimental animals. The MAC values are set lower than the experimentally determined NOAEL due to the uncertainty factors (UF) reflecting interspecies and intraspecies differences, differences in duration of exposure, issues related to dose-response relationship and quality of data [1].

Uncertainty factor (UF) is calculated using the formula:

$$
\mathrm{UF}=\mathrm{A} \times \mathrm{B} \times \mathrm{C} \times \mathrm{D} \times \mathrm{E}
$$

where:

A - max 2 - average human to sensitive human,

B - max 10 - for tests using exposures other than inhalation; $\max 3$ - for tests using inhalation exposure,
C - max 3 - short term to long-term exposure,

D - max 3 - extrapolation from the lowest-observed-adverseeffect level (LOAEL) to NOAEL,

E - max 5 - modifying factor (related to expert's opinion on the comprehensiveness and possible long-term effects).

Calculating of MAC values for substances with systemic activity [1]:

1. The dose of the substance absorbed by the animal $\left(\mathrm{D}_{\mathrm{w}}\right)$, is given in $\mathrm{mg} / \mathrm{kg} /$ day, and calculated from the formula:

$$
\mathrm{D}_{\mathrm{W}}=\mathrm{NOAEL} \times \mathrm{V} \times \mathrm{T} / \mathrm{W}
$$

where:

$\mathrm{V}$ - volume of air inhaled by the animal ( $\mathrm{m}^{3} /$ day),

$\mathrm{T}$ - time of exposure (days),

$\mathrm{W}$ - mean weight of the animal $(\mathrm{kg})$.

2. The extrapolation of the dose of substance absorbed by the animal to humans $\mathrm{D}_{\mathrm{C}}\left(\mathrm{g} / \mathrm{m}^{3}\right)$ :

$$
\mathrm{D}_{\mathrm{C}}=\mathrm{D}_{\mathrm{W}} \times \mathrm{W}_{\mathrm{H}} / \mathrm{V}_{\mathrm{H}}
$$

where:

$\mathrm{W}_{\mathrm{H}}$ - mean weight of the human,

$\mathrm{V}_{\mathrm{H}}$ - volume of air inhaled by the human during $8 \mathrm{~h}$.

3. Calculation of MAC value from the formula:

$$
\mathrm{MAC}=\mathrm{D}_{\mathrm{C}} / \mathrm{UF}
$$

where:

$\mathrm{D}_{\mathrm{C}}$ - dose of the substance absorbed by the animal $\left(\mathrm{mg} / \mathrm{m}^{3}\right)$, $\mathrm{UF}$ - uncertainty factor.

4. Calculation of MAC for irritant substances:

$$
\mathrm{MAC}=\mathrm{NOAEL} / \mathrm{UF}
$$


Uncertainty factor (UF) to 5 resulting from interspecies differences and human sensitivity.

5. Calculation of MAC values from $\mathrm{RD}_{50}$ data (exposure concentration producing a $50 \%$ respiratory rate decrease in mice exposed to a geometric series of concentrations of airborne irritants) [1,18].

The above data serve to calculate the values of the MAC for the substances which irritate the airways. A MAC value determined as $\mathrm{RD}_{50}$ is selected from the range between $1 / 10$ and $1 / 100$ concentration values causing an irritation in the animals (Table 1).

Table 1. Calculation of maximum admissible concentrations (MACs) from exposure concentration producing a 50\% respiratory rate decrease in mouse exposed to a geometric series of concentrations of airborne irritants $\left(\mathrm{RD}_{50}\right)$

\begin{tabular}{ll}
\hline $\begin{array}{c}\text { Concentration of } \\
\text { substance causing } \\
\text { an irritation in the } \\
\text { animals }\end{array}$ & $\begin{array}{c}\text { Expected effects of the irritating } \\
\text { activity of the substances in humans }\end{array}$ \\
\hline $\mathrm{RD}_{50}$ & $\begin{array}{l}\text { concentration tolerated by humans } \\
\text { concentration resulting in slight } \\
1 / 10 \mathrm{RD}_{50}\end{array}$ \\
$1 / 100 \mathrm{RD}_{50}$ & $\begin{array}{l}\text { irritation of eyes, nose and throat } \\
\text { none or very slight irritating activity }\end{array}$ \\
\hline
\end{tabular}

6. If an experiment is lacking a clear NOAEL/LOAEL, benchmark dose (BMD) is applied in health risk assessment and for setting limit values. BMD is the lower limit of the confidence interval, e.g., $95 \%$ for the level of exposure (or dose taken), which may cause a small increase, e.g., 5 or $10 \%$ of the incidence of health effects [1].

The MACs refer exclusively to concentrations of chemicals in the air, i.e., the values only prevent adverse effects if no skin absorption occurs. Where contact chemicals with skin can add significantly to the body burden in addition to that caused by inhalation, a skin notation should be used [19]. In Poland, the skin notation (Sk) was set mainly based on a dermal $\mathrm{LD}_{50}$ being below $1000 \mathrm{mg} / \mathrm{kg}$ and it occurs only in the Commission booklet "Harmful agents in the working environment - limit values" [20].

\section{Setting occupational exposure limits for carcinogenic compounds}

For carcinogenic agents, the Polish MAC Commission has adopted socially accepted risk at the level of $10^{-4}$ to $10^{-3}$. That means that Polish society has accepted the possibility of the extra risk of one cancer per 10000 or 1000 people exposed to a carcinogenic substance. At the same time when MACs are established for compounds that have been proven to be carcinogens or mutagenic, their admissible concentrations are lowered. Enterprises in which carcinogenic or mutagenic substances are found, should strive to eliminate them from technological processes or maintain their concentrations below maximum admissible values, at a possibly low level. Moreover, endeavors should be made to minimize exposure to non-threshold carcinogenic substances [21]. When preparing draft MAC values for carcinogenic substances, health risk assessment resulting from human exposure to the carcinogens can be also used. The following considerations have been valid when performing the assessment based on the results of animal studies [21]:

- The relationship between the dose (expressed in suitable units) and tumor frequency in animals is determined from the results of biological research on animals.

- The dose-response relationship is the same in humans and in the animals.

- Both $\mathrm{mg} / \mathrm{kg}$ body weight and $\mathrm{mg} / \mathrm{m}^{2}$ body surface area per diem may be used as the suitable units of the equivalent dose.

- The carcinogenic activity after received small doses is linear.

The experts who prepare the documentation and propose the MAC for carcinogen or mutagen should use the following terms: risk, accepted risk, unit risk, slope factor [21]. To-date, the MAC values have been set for 49 carcinogenic chemicals and 3 dusts [20,22]. 
Work involving exposure to carcinogenic agents is prohibited for pregnant and breast-feeding women, and for juvenile workers. This results from the regulation of the Council of Ministers on the list of the types of work that are particularly strenuous or harmful to women's health [23] and the regulation of the Council of Ministers on the list of jobs prohibited for juvenile people [24].

\section{Biological monitoring}

Biological monitoring entails the measurement of substances and/or metabolites in biological media, and the measurement of biological effects induced by the substances.

The Interdepartmental Commission also propose BEI values, but they are regarded only as recommended values. They are published in a Commission booklet "Harmful agents in the working environment - limit values." The last issue of the booklet was published in 2012. The Commission has established BEIs for 33 chemical substances [20]. In Poland, only workers exposed to lead in the working environment must be tested for their blood lead content - this test has been made obligatory by the regulation of the Minister of Health of December 30, 2004 on safety and health related to the prevalence of chemicals in the workplace [25].

\section{DISCUSSION AND CONCLUSIONS}

The process of harmonizing exposure limits in EU countries began with the establishment of indicative occupational exposure limit values (IOELVs) by the Scientific Committee on Occupational Exposure Limits (SCOEL) [8].

Indicative occupational exposure limit values are healthbased, non-binding values established on the basis of newest data and with the use of available measuring techniques. They determine threshold exposure levels below which exposure is not expected to result in adverse health effects [10-13]. IOELVs are necessary for determination and assessment of risk by the employer in accordance with Art. 4 of Directive 98/24/EC [9].
For every chemical agent for which indicative occupational exposure limit values have been established at the Community level, the Member States have been obliged to determine the national occupational exposure value, taking into account the Community admissible value.

For some non-threshold carcinogenic substances for which IOELVs cannot be set, BOELVs (binding occupational exposure limit values) have been adopted. They are established on the basis of currently available scientific data, socio-economic conditions and technical feasibility of achieving these values in industry. Contrary to IOELVs, which are implemented into EU law by the Council Directive, BOELVs are introduced by the decision of the European Commission and European Parliament. For substances for which BOELVs have been set, Member States establish appropriate national values which may be at the same or lower levels than the values established by the EU. The binding values have been set for the following substances: asbestos (actinolite, anthophyllite, chrysotile, gruenerite, crocidolite, tremolite), benzene, hardwood dusts, lead and its inorganic compounds, vinyl chloride monomer [9,14,15].

Transposition of directives containing indicative values for 122 chemicals required inclusion since 2002 to the Polish list of MAC (TWA) 3 new chemicals (2-(2-butoxyethoxyethanol, neopentane, bisphenol A), and reducing the occupational exposure limits for 41 chemicals.

However, for 8 substances (ethylamine, butan-2-one, ethyl benzene, pentane, cresol - a mixture of isomers, $\mathrm{N}, \mathrm{N}$-dimethylformamide, methyl methacrylate, 1,4-dioxane) in the light of current data MAC (TWA) value was increased. For 70 chemicals, earlier Polish MAC (TWA) and/or MAC (STEL) values have remained unchanged (Figure 3).

Implementation in the Polish law of the directives specifying the binding limit values resulted in reduction of the MAC (TWA) for dust containing asbestos (6 types). For other 4 compounds (benzene, hardwood dust, lead and its 


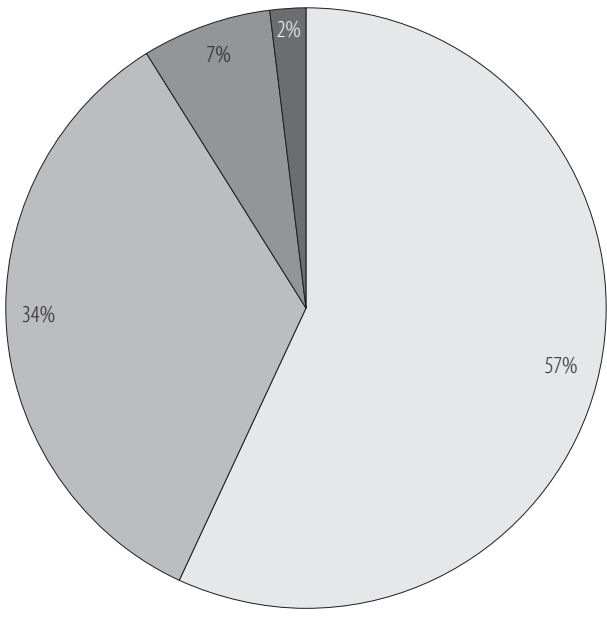

substances for which MAC (TWA) does not have to be changed in relation to IOELV substances for which MAC (TWA) has been reduced to IOELV

$\square$ substances for which MAC (TWA) value increased to IOELV

substances for which new MAC (TWA) has been based on IOELV

MAC (TWA) - as in Figure 2.

Fig. 3. Transposition of the directives on indicative occupational exposure limit values (IOELV) for 122 chemicals to Polish regulations

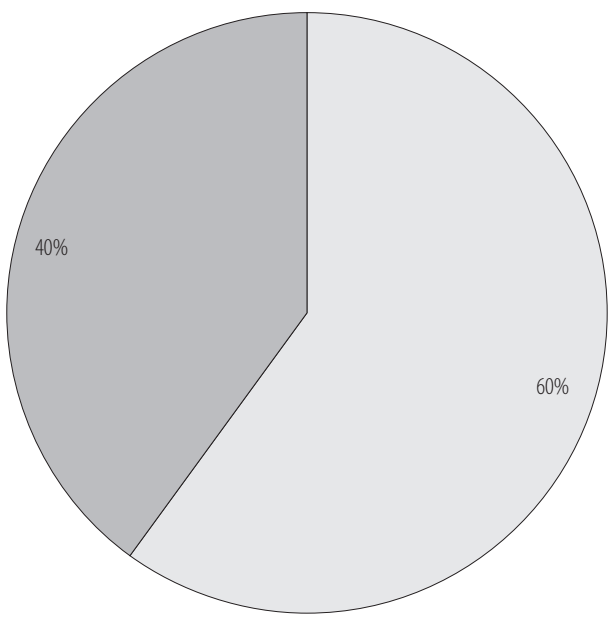

substances for which the MAC (TWA) has been reduced to the BOELV

substances for which the MAC (TWA) were lower than the BOELV

MAC (TWA) - as in Figure 2.

Fig. 4. Transposition of the directives on binding occupational exposure limit values (BOELV) for 10 chemicals to Polish regulations inorganic compounds, vinyl chloride) MAC (TWA) values are compatible with the EC BOELV values [5] (Figure 4).

The scientific basis for MACs in Poland are in line with EU principles. For some adverse effects (in particular carcinogenicity and genotoxicity), it is - according to current knowledge - impossible to identify such limits. In these cases, the Polish MAC Commission recommends values of the socially accepted risk. The system for establishing MACs has to produce a certain number of new and revised values each year to keep up with the growing number of substances used in the industry.

In a book "Global Occupational Exposure Limits for over 6000 Specific Chemicals" the authors have analyzed over 6000 chemical exposure limits from 50 countries and 15 organizations [26]. They have revealed some interesting variations and trends:

- For a global economy to work satisfactorily, all participants in the working environment should be using the same high standards. They all should be sharing their cumulative knowledge and experience in the area of worker safety and health to the benefit of all.

- The most countries have OELs that date back to 2003 or more recent.

- Most countries have 3 sets of OELs. One for dusts, one for carcinogens and one for volatile or gaseous chemicals. Many countries also have separate standards for lead and asbestos.

- The OEL definition in a number of countries clearly state that OELs do not protect sensitive workers.

- The EU has established minimum uniform OEL standards for all EU countries. These include standards for carcinogens. EU members must adopt these as minimum standards.

- A number of countries adjust their OELs for altitude.

- A number of countries adjust their OELs for standard temperature and pressure.

- Of the 6000+ OELs worldwide, over 4200 are regulated in more than 1 country [25]. 
The overview on Occupational Exposure Limits (OELs) at the European and Member States level (25 countries in 2007) showed that the levels of OEL values were equal or very similar in most of the Member States. The lowest deviation in some Member States was 50\% of the limit value chosen by the majority, in other cases, the highest OEL value was set at $200 \%$ of the average Member States value.

The largest difference was identified for acrylamide; OEL values differed by a factor of 10 between 2 Member States at the upper end and 2 Member States at the lowest end.

The same deviations were recorded for the short term and peak levels (10 lists contain such levels), which were also found to be very similar between the Member States.

The sources of scientific background knowledge for OELs are mixed in the majority of Member States. Some Member States have their own scientific committee for the development and discussion of OELs. Many different descriptions and definitions are in use, such as: OELV (IR), WEL (UK) (formerly OES and MEL), OEL (E), LV (DK), LLV (S), MAC (NL, DE, PL) and BOELV/IOELV (EU) [27].

Within the frame of the Community regulation on chemicals and their safe use (REACH), the DNELs (Derived No Effect Levels) have been introduced in Europe [28]. These represent levels of exposure above which humans (including consumers, workers, etc.) should not be exposed. Manufacturers and importers are required to calculate DNELs as part of their chemical safety assessment (CSA) for any chemical used in quantities of $10 t$ or more per year. DNELs reflect the likely routes and duration and frequency of exposure. If more than 1 route of exposure is likely to occur (oral, dermal or inhalation), then a DNEL must be established for acute and repeated exposure, for each route of exposure and for the exposure from all routes combined. It may also be necessary to identify different DNELs for each relevant human population (e.g., workers, consumers or humans subject to exposure indirectly via the ambient environment) and possibly for certain vulnerable sub-populations (e.g., children, pregnant women) [28].

The starting point in establishing DNELs is a NOAEL or a LOAEL from human data or animal studies. The next step in the calculation of a DNEL is to address assessment factors by extrapolation from experimental data to a real human exposure situation [29]. Thus, up to 15 DNELs may be defined for each substance. DNELs calculated by individual manufacturers and importers are not subject to any requirement for consultation or to any opportunity to be modified by other interested parties [28,29]. The IOELVs or BOELVs are set via a well-established process involving Scientific Committee on Occupational Exposure Limits (SCOEL), governmental, employers' and workers' representatives [30,31].

Which level should be used to assess workers' inhalation exposure in the workplace: an EU IOELV or manufacturer's DNEL?

In the opinion of some scientist, it is unacceptable for limit values that are relevant to occupational exposure, to be set in the context of other EU legislation. But the DNEL for 2-butyne-1,4-diol according to REACH was lower than any corresponding health-based OEL for that chemical. According to the authors, this indicates that the OEL does not provide the appropriate level of protection required by REACH [31].

\section{REFERENCES}

1. Czerczak S. [The principles of establishing MAV values of harmful chemical compounds in the working environment]. Princip Meth Assess Work Environ. 2004;4(42):5-18. Polish.

2. [The Regulation of Ministry of Labor, Earnings and Social Policy of 22 December 1982 on the maximum admissible concentrations and intensities of harmful to health agents in the working environment. J Laws 1982, No. 43, item 287]. Polish. 
3. [The Order No. 33 of Ministry of Labor, Earnings and Social Policy and Ministry of Health and Social Welfare of 27 June 1983 on the organization the Interdepartmental Commission for Actualization the List of Maximum Admissible Concentrations and Intensities for Agents Harmful to Health in the Working Environment]. Bull Interdepl Commr Updating List Max Admis Concentr Intensities Agents Harmful Health Work Environ. 1985;1:47-50. Polish.

4. [The Ordinance of Prime Minister of 15 December 2008 on the organization of the Interdepartmental Commission for Maximum Admissible Concentrations and Intensities for Agents Harmful to Health in the Working Environment. J Laws 2008, No. 225, item 1490 (December 22, 2008)]. Polish.

5. [The regulation of the Minister of Labor and Social Policy of 29 November 2002 on the maximum admissible concentrations and intensities of harmful to health agents in the working environment. J Laws 2002, No. 217, item 1833, changes J Laws 2005, No. 212, item 1769; J Laws 2007, No. 161, item 1142; J Laws 2009, No. 105, item 873; J Laws 2010, No. 141, item 950; J Laws 2011, No. 274, item 1621]. Polish.

6. The Threshold Limit Values (TLVs ${ }^{\circledR}$ ) and Biological Exposure Indices (BEIs $\left.{ }^{\circledR}\right)$. Cincinnati: ACGIH; 2013.

7. Paustenbach DJ. The history and biological basis of occupational exposure limits for chemical agents. 5th ed. In: Harris RL, editor. Patty's Industrial Hygiene. Vol. 3. New York: John Wiley and Sons; 2000. p. 1903-2000.

8. Commission Decision 95/320/EC of 12 July 1995 setting up a Scientific Committee for Occupational Exposure Limits to Chemical Agents. Off J Eur Union 188, 09.08.1995, p. 14-15 (Aug 9, 1995).

9. Council Directive 98/24/EC of 7 April 1998 on the protection of the health and safety of workers from the risks related to chemical agents at work (fourteenth individual Directive within the meaning of Article 16(1) of Directive 89/391/EEC). Off J Eur Union 131, 5.5.1998, p. 11-23 (May 5, 1998).

10. Commission Directive 91/322/EEC of 29 May 1991 on establishing indicative limit values by implementing Council
Directive 80/1107/EEC on the protection of workers from the risks related to exposure to chemical, physical and biological agents at work. Off J Eur Union 177, 5.7.1991, p. 22 (Jul 5, 1991).

11. Commission Directive 2000/39/EC of 8 June 2000 establishing a first list of indicative occupational exposure limit values in implementation of Council Directive 98/24/EC on the protection of the health and safety of workers from the risks related to chemical agents at work. Off J Eur Union 142, 16.6.2000, p. 432 (Jun 16, 2000).

12. Commission Directive 2006/15/EC of 7 February 2006 establishing a second list of indicative occupational exposure limit values in implementation of Council Directive 98/24/ EC and amending Directives 91/322/EEC and 2000/39/EC. Off J Eur Union 38, 9.2.2006, p. 36 (Feb 9, 2006).

13. Commission Directive 2009/161/EC of 17 December 2009 establishing a third list of indicative occupational exposure limit values in implementation of Council Directive 98/24/ EC and amending Commission Directive 2000/39/EC. Off J Eur Union 338, 19.12.2009, p. 87-89 (Dec 19, 2009).

14. Commission Directive 2004/37/EC of the European Parliament and of the Council of 29 April 2004 on the protection of workers from the risks related to exposure to carcinogens or mutagens at work (Sixth individual Directive within the meaning of Article 16(1) of Council Directive 89/391/EEC). Off J Eur Union 158, 30.4.2004, p. 50-76 (Jun 29, 2004).

15. Directive 2009/148/EC of the European Parliament and of the Council of 30 November 2009 on the protection of workers from the risks related to exposure to asbestos at work. Off J Eur Union 330, 16.12.2009, p. 28 (Dec 16, 2009).

16. Pośniak M, Skowroń J. Harmful chemical agents in the working environment. In: Koradecka D, editor. Handbook of occupational safety and health. Boca Raton: CRC Press Taylor \& Francis Group; 2010. p. 103-37.

17. Nielsen GD, Ovrebo S. Background, approaches and recent trends for setting health-based occupational exposure limits: A minireview. Regul Toxicol Pharmacol. 2008;51:253-69, http://dx.doi.org/10.1016/j.yrtph.2008.04.002. 
18. Yu K, Alexeeff GV, Broadvin R, Salmon AG. Evaluation and application of the RD50 for determining acceptable exposure levels of airborne sensory irritants for the general public. Environ Health Perspect. 2007;115(11):1609-16, http://dx.doi.org/10.1289/ehp.9848.

19. Czerczak S, Kupczewska M. Assignment of skin notation for maximum allowable concentration (MAC) list in Poland. Appl Occup Environ Med. 2002;55:795-804.

20. Augustyńska D, Pośniak M. [Harmful agents in the working environment - Limit values]. Warszawa: CIOP-PIB; 2012. Polish.

21. Skowroń J, Czerczak S. [Principles for establishing occupational exposure limits for carcinogens in Poland and other EU countries]. Med Pr. 2013;64(4):541-63, http://dx.doi. org/10.13075/mp.5893.2013.0046. Polish.

22. Skowroń J. [Carcinogenic and mutagenic agents in Polish and UE legal regulations]. Princip Meth Assess Work Environ. 2007 [cited 2002 Aug 12];4(54):5-43. Available from: http://www.ciop.pl/17374.html. Polish.

23. [The regulation of the Council of Ministers of 10 September 1996 on the list of the types of work that are particularly strenuous or harmful for women's health. J Laws 1996, No. 114, item 545; changed J Laws 2002, No. 127, item 1092]. Polish.

24. [The regulation of the Council of Ministers of 25 August 2004 on jobs prohibited to juvenile people and the conditions of employing them for some of those jobs. J Laws 2004, No. 200, item 2047; J Laws 2006, No. 107, item 724, changes J Laws 2006, No. 107, item 724]. Polish.

25. [The regulation of the Minister of Health of 30 December 2004 on safety and health related to the prevalence of chemicals in the workplace. J Laws 2005, No. 11, item 86]. Polish.
26. Brandys RC, Brandys GM; Occupational \& Environmental Health Consulting Services, Inc. Global occupational exposure limits for over 6,000 specific chemicals. 2nd ed. Occupational \& Environmental Health Consulting Services; 2008.

27. To prepare a policy overview of occupational exposure limits for publication on the Agency's dangerous substances web area. Bilbao: The European Agency for Safety and Health at Work, Task TC WE 3.3; 2006 [not published].

28. Regulation (EC) No. 1907/2006 of the European Parliament and of the Council of 18 December 2006 concerning the Registration, Evaluation, Authorization and Restriction of Chemicals (REACH), establishing a European Chemical Agency, amending Directive 1999/45/EC and repealing Council Regulation (EEC) No. 793/93 and Commission Regulation (EC) No. 1488/94 as well as Council Directive 76/769/EEC and Commission Directives 91/155/EEC, 93/67/EEC, 93/105/EC and 2000/21/EC. Off J Eur Union. 2006;396:1-849. Available at: http://eur-lex.europa.eu/LexUriServ/LexUriServ.do?uri= OJ:L:2006:396:0001:0849:EN:PDF.

29. Guidance on assessment factors to derive a DNEL. ECETOC, Technical Report No. 110, 2010 [cited 2014 Feb 20]. Available from: http://www.ecetoc.org/publications.

30. Scientific Committee on Occupational Exposure Limits: Methodology for the derivation of occupational exposure limits: Key documentation (version 7). European Commission Directorate-General for Employment, Industrial Relation and Social Affairs, 2013 [cited 2014 Feb 20]. Available from: http://ec.europa.eu/social/main.jsp?catId=148\&langI $\mathrm{d}=$ en\&intPageId $=684$.

31. Kupczewska-Dobecka M, Świercz R. [Setting limit values for chemical substances in the workplace: DNELinh setting according to REACH principles following the example of 2-butyne-1,4-diol]. Med Pr. 2009;60(5):347-57. Polish.

This work is available in Open Access model and licensed under a Creative Commons Attribution-NonCommercial 3.0 Poland License - http://creativecommons.org/ licenses/by-nc/3.0/pl/deed.en. 